\title{
Do successive climate extremes weaken the resistance of plant communities? An experimental study using plant assemblages
}

\author{
F. E. Dreesen, H. J. De Boeck, I. A. Janssens, and I. Nijs \\ Correspondence to: F. E. Dreesen (freja.dreesen@ua.ac.be) \\ Received: 28 March 2013 - Published in Biogeosciences Discuss.: 10 June 2013 \\ Revised: 28 October 2013 - Accepted: 15 November 2013 - Published: 8 January 2014
}

Research Group of Plant and Vegetation Ecology, Department of Biology, University of Antwerp, Wilrijk, Belgium

\begin{abstract}
The probability that plant communities undergo successive climate extremes increases under climate change. Exposure to an extreme event might elicit acclimatory responses and thereby greater resistance to a subsequent event, but might also reduce resistance if the recovery period is too short or resilience too low. Using experimental herbaceous plant assemblages, we compared the effects of two successive extremes occurring in one growing season (either two drought extremes, two heat extremes or two drought + heat extremes) to those of assemblages being exposed only to the second extreme. Additionally, the recovery period between the successive extremes was varied $(2,3.5$ or 6 weeks).

Among the different types of climate extremes, combined heat + drought extremes induced substantial leaf mortality and plant senescence, while the effects of drought and heat extremes were smaller. Preceding drought + heat extremes lowered the resistance in terms of leaf survival to a subsequent drought + heat extreme if the recovery period was two weeks, even though the leaves had completely recovered during that interval. No reduced resistance to subsequent extremes was recorded with longer recovery times or with drought or heat extremes. Despite the substantial mortality on the short term, the drought + heat and the heat extremes increased the end-of-season aboveground biomass independent of the number of extreme events or the duration of the recovery period. These results show that recurrent climate extremes with short time intervals can weaken the resistance of herbaceous plant assemblages. This negative effect in the short term can, however, be compensated in the longer term through rapid recovery and secondary positive effects.
\end{abstract}

\section{Introduction}

In a future climate, many ecosystems will be exposed to more frequent and more intense climate extremes (Fischer and Schär, 2010; IPCC, 2012; Meehl et al., 2000). Although not all extreme events will necessarily have a noticeable or immediate ecological impact (Dreesen et al., 2012; Kreyling et al., 2008; Smith, 2011; Leuzinger et al., 2005), many of them, especially drought events, can lead to disastrous changes in ecosystems, as observed following naturally occurring extremes (Bréda et al., 2006; Breshears et al., 2005; Ciais et al., 2005; Peñuelas et al., 2007) and in studies experimentally inducing climate extremes (De Boeck et al., 2011). Moreover, the increasing probability of recurrent extremes such as consecutive severe droughts and heat waves (IPCC, 2012) might impose an even stronger threat for ecosystems than single extreme events if negative effects accumulate and eventually lead to chronic stress.

With recurring climate extremes, the ability to recover from a first event can play an important part in the effect of subsequent climate extremes. For example, trees with limited recovery from a drought event have been shown to be more sensitive to a second drought occurring several years later (Lloret et al., 2004). Lack of sufficient resilience (capacity of an ecosystem to reach pre-disturbance performance levels) can thus compromise resistance (ability of an ecosystem to withstand displacement from control levels) to a subsequent event. The ability to recover not only is species-specific (Gallé et al., 2011; Liu et al., 2010) but is also influenced by competitive interactions, plant age or size (Lloret et al., 2004), the intensity of the past drought (Miyashita et al., 2005), and the amount of stored carbon reserves (Galiano et al., 2011). Importantly, recovery can be delayed when 
drought events are repeated, as reported in Liu et al. (2010). Evidence that repeated events can impair resilience or resistance was also given by Zavalloni et al. (2009), who observed that frequent mild drought events evoked by simulated climate warming enhanced stress levels in grasslands and lowered the resistance to a severe drought event. In Arctic tundra, loss of temperature resistance has been reported when plants had previously been exposed to successive heat extremes (Marchand et al., 2006). Over time, such losses of resistance and/or resilience could lead to species shifts and even move the system into an alternative state (Scheffer et al., 2001).

In contrast to losing resistance, plants might also become more resistant to future exposures after being subjected to a first event through physiological, genetic or biochemical acclimation (Bruce et al., 2007). For example, pre-treatment with heat often brings greater tolerance to subsequent heat (Wahid et al., 2007; Xu et al., 2006). Several plant species have also been found to acclimate to multiple drought cycles (Gallé et al., 2011; Luo et al., 2011) even when the aboveground parts were harvested before the following drought period (Walter et al., 2011). Drought preconditioning is sometimes applied to improve the drought resistance of seedlings or young plants used for restoration or plantations (Guarnaschelli et al., 2006; Ruiz-Sánchez et al., 2000; Vilagrosa et al., 2003; Villar-Salvador et al., 2004).

Most of our knowledge on the impact of recurring climate events relates to repeated droughts. However, the incidence of higher temperatures (e.g. heat waves) during drought will exacerbate the response, as warming accelerates soil drying and increases plant water demands. In this study, plant assemblages were subjected to two successive extreme events with the same historical intensity. These events were either two drought periods, two heat waves or two periods with combined heat and drought. We varied the time interval between the two events (either 6, 3.5 or 2 weeks) in order to study the effect of the recovery period between the events on mortality and productivity. The responses to the two successive extremes were compared with responses of assemblages being exposed to only the second extreme in order to evaluate whether a preceding event increased, decreased or did not affect the vulnerability. We expected that the impact caused by the second extreme event would depend on the elapsed time interval. In the scenario with the longest delay between the successive extremes, we hypothesized that acclimation could occur, enhancing the resistance to drought and/or heat. With short time intervals between the extremes, on the other hand, we anticipated additional detrimental effects on plant and leaf mortality, and hence a lower end-of-season biomass.

\section{Materials and methods}

\subsection{Experimental design}

The experiment was conducted in 2010 at an experimental field site located at the University of Antwerp (Belgium, $\left.51^{\circ} 9^{\prime} \mathrm{N}, 4^{\circ} 24^{\prime} \mathrm{E}\right)$. Mean annual air temperature at this location with temperate maritime climate is around $9.6^{\circ} \mathrm{C}$, and mean annual precipitation is $780 \mathrm{~mm}$, equally distributed over the year. Synthesized plant assemblages were used, which were constructed in separate containers $(20 \mathrm{~cm}$ diameter, $40 \mathrm{~cm}$ depth). These assemblages consisted of 10 individuals belonging to three perennial herbaceous species (Plantago lanceolata L., Rumex acetosella L. and Bellis perennis L.). Plant individuals were sown in the previous year and were transplanted to the containers in spring in a hexagonal grid with only interspecific neighbours. We opted to use experimental plant assemblages because this ensures good comparability among treatments, and thus a more easy detection of mechanisms than in natural systems, where differences in soil structure, nutrient availability, species composition and plant density can more easily obfuscate results. The plant species used were common in local grasslands and small-statured, ensuring uniform exposure to the infrared heating treatment (see below). The containers were filled with sandy soil (96\% sand, $1.5 \%$ silt and $2.5 \%$ clay; $\mathrm{pH} 7.6 ; 1.3 \% \mathrm{C}, 19 \mathrm{mg}$ nitrate-N, $1.1 \mathrm{mg}$ ammonium-N and $550 \mathrm{mg}$ Kjeldahl-N per kg dry soil) and were placed in watertight boxes $(135 \mathrm{~cm} \times 135 \mathrm{~cm})$. These boxes, six in total, were embedded in the soil to ensure natural soil temperature profiles. When not exposed to drought, the boxes were provided with a constant water table $(34 \mathrm{~cm}$ below the soil surface) to ensure that all assemblages had sufficient water. A perforated lid at the bottom of each container allowed for both water drainage and inflow. Permanent rain shelters were installed above each box to eliminate precipitation. The shelters $(3.60 \mathrm{~m} \times 3.60 \mathrm{~m})$ had transparent polycarbonate roofs (thickness $4 \mathrm{~mm}$, light attenuation around 5-15\%, depending on solar angle) and a height of $2.40 \mathrm{~m}$ that slanted down to $1.80 \mathrm{~m}$ in south-west direction and to $2 \mathrm{~m}$ in north-east direction. The height of the shelters ensured full air exchange with the surroundings, and both the build-up of heat $\left(+0.2^{\circ} \mathrm{C}\right.$ on average) and changes in relative humidity ( $+3 \%$ on average) were modest.

The extreme climatic treatments included drought (D), heat $(\mathrm{H})$ and the combination of drought and heat $(\mathrm{DH})$. The plant assemblages were exposed to either (i) a control situation without extremes (C), (ii) two consecutive climate extremes $(\mathrm{D}+\mathrm{D}, \mathrm{H}+\mathrm{H}, \mathrm{DH}+\mathrm{DH})$, or (iii) only the second climate extreme $(\mathrm{C}+\mathrm{D}, \mathrm{C}+\mathrm{H}, \mathrm{C}+\mathrm{DH})$. Key to the design is the comparison between (ii) and (iii), which allows for determination of whether a preceding extreme affects the response to a subsequent extreme. The second extreme event was applied at the same time in all plant assemblages (12 August to 6 September; see Sect. 2.2), but the time between the 
Table 1. Overview of different scenarios and treatments with number of replicate experimental plant assemblages per treatment, length of the drought events and the average daily maximal temperatures during the heat waves. $\mathrm{C}=$ control, $\mathrm{D}=\mathrm{drought}, \mathrm{H}=\mathrm{heat}$, and $\mathrm{DH}=\mathrm{drought}$ + heat. $*=$ highest average daily $T_{\max }$ at the height of the canopy observed in the control plots during the entire period (DOY 153-225) preceding the second event.

\begin{tabular}{|c|c|c|c|c|c|c|c|c|}
\hline \multirow[t]{2}{*}{ Scenario } & \multirow{2}{*}{$\begin{array}{c}\text { Interval } \\
\text { (days) }\end{array}$} & \multicolumn{2}{|c|}{ Treatments } & \multirow{2}{*}{$\begin{array}{l}\text { No. of plant } \\
\text { assemblages }\end{array}$} & Average daily & Drought & Average daily & Drought \\
\hline & & 1 st event & 2nd event & & \multicolumn{2}{|c|}{1 st event } & \multicolumn{2}{|c|}{ 2nd event } \\
\hline & & C & C & 27 & $29.3^{*}$ & 0 & 23.4 & 0 \\
\hline IV & 42 & D & D & 15 & 27.9 & 25 & 23.4 & 25 \\
\hline IV & 42 & $\mathrm{H}$ & $\mathrm{H}$ & 15 & 32.6 & 0 & 30.2 & 0 \\
\hline IV & 42 & DH & DH & 15 & 32.6 & 25 & 30.2 & 25 \\
\hline III & 25 & D & D & 15 & 30.9 & 19 & 23.4 & 25 \\
\hline III & 25 & $\mathrm{H}$ & $\mathrm{H}$ & 15 & 34.5 & 0 & 30.2 & 0 \\
\hline III & 25 & DH & DH & 15 & 34.5 & 19 & 30.2 & 25 \\
\hline II & 14 & D & D & 15 & 29.1 & 20 & 23.4 & 25 \\
\hline II & 14 & $\mathrm{H}$ & $\mathrm{H}$ & 15 & 32.9 & 0 & 30.2 & 0 \\
\hline II & 14 & DH & DH & 15 & 32.9 & 20 & 30.2 & 25 \\
\hline I & I & C & D & 9 & $29.3^{*}$ & I & 23.4 & 25 \\
\hline I & 1 & C & $\mathrm{H}$ & 9 & $29.3^{*}$ & I & 30.2 & 0 \\
\hline I & I & $\mathrm{C}$ & DH & 9 & $29.3^{*}$ & I & 30.2 & 25 \\
\hline Total & & & 3 & 189 & & & & \\
\hline
\end{tabular}

end of the first event and the start of the second was varied (42, 25 or 14 days). The assemblages that were exposed to the two consecutive extremes thus included three different climate scenarios combined with three different interval times. The entire setup consisted of 189 plant assemblages, of which 45 assemblages were exposed to the 2 subsequent extreme events with a 42-day interval (further referred to as scenario IV) at 15 replicate assemblages per climate treatment $(\mathrm{D}+\mathrm{D}, \mathrm{H}+\mathrm{H}$ or $\mathrm{DH}+\mathrm{DH}$, see Table 1$)$. A similar number of plant assemblages $(3 \times 15)$ was exposed to the 2 extreme events with a 25 -day interval (scenario III) and with a 14-day interval (scenario II). In addition, 27 assemblages were exposed only to the common extreme in August (scenario I) at 9 replicate assemblages per treatment $(C+D$, $\mathrm{C}+\mathrm{H}$ or $\mathrm{C}+\mathrm{DH})$. Due to space limitations in the experimental setup, scenario I had a lower number of replicate assemblages. The remaining 27 assemblages were subjected to the control climate (see Table 1 for overview of treatments and scenarios).

Each of the six watertight boxes enclosing the plant assemblages was separated into two halves. In each box, the water table was maintained in one half ( $\mathrm{C}$ and $\mathrm{H}$ treatments), while in the other half, drought was induced at the appropriate time by removing the water table and withholding irrigation (D and DH treatments). Of the 12 halves in total, 3 were filled with control assemblages (initially 54 control assemblages), and the other 9 halves were assigned to the treatments $\mathrm{D}, \mathrm{H}$ or DH in either scenario IV, III or II. Before the common second extreme event was initiated, 27 control plant assemblages were spread over the 9 non-control halves. These 27 former control assemblages became the plant assemblages used for scenario I ( 9 per treatment), which were thus subjected to the second climate extreme only (see Table 1). Figure S1 in the Supplement gives a schematic overview of the experimental setup, showing the distribution of the plant assemblages during the second extreme event. In the period between the two successive events, all assemblages were relocated between the halves (to avoid pseudo-replication).

Above three of the six boxes (containing the $\mathrm{H}$ and $\mathrm{DH}$ treatments), a set of six $1500 \mathrm{~W}$ infrared lamps (spectrum $0.7-3 \mu \mathrm{m}$ ) was suspended at a height of circa $1.2 \mathrm{~m}$ to allow direct and uniform heating of the canopy in a nonintrusive way. The three other boxes ( $\mathrm{C}$ and $\mathrm{D}$ treatments) had dummy lamps and were exposed to ambient air conditions. The power output of the heaters was adjusted to match the target maximum daily air temperatures (see Sect. 2.2).

Campbell CS616 soil water content (SWC) reflectometers (Campbell Scientific Ltd, Loughborough, UK) were installed in four assemblages per half-box (i.e. 48 sensors in total). These sensors were $30 \mathrm{~cm}$ long, covering most of our soil profile. The values were recorded hourly by a data logger (DL2E, Delta T, Cambridge, UK) and corrected using an in situ calibration. Water retention curves were established by an external soil laboratory to determine the soil moisture content at field capacity $(\mathrm{pF} 2.5)$ and at permanent wilting point ( $\mathrm{pF} 4.2$ ), which were 15 and 3.7 

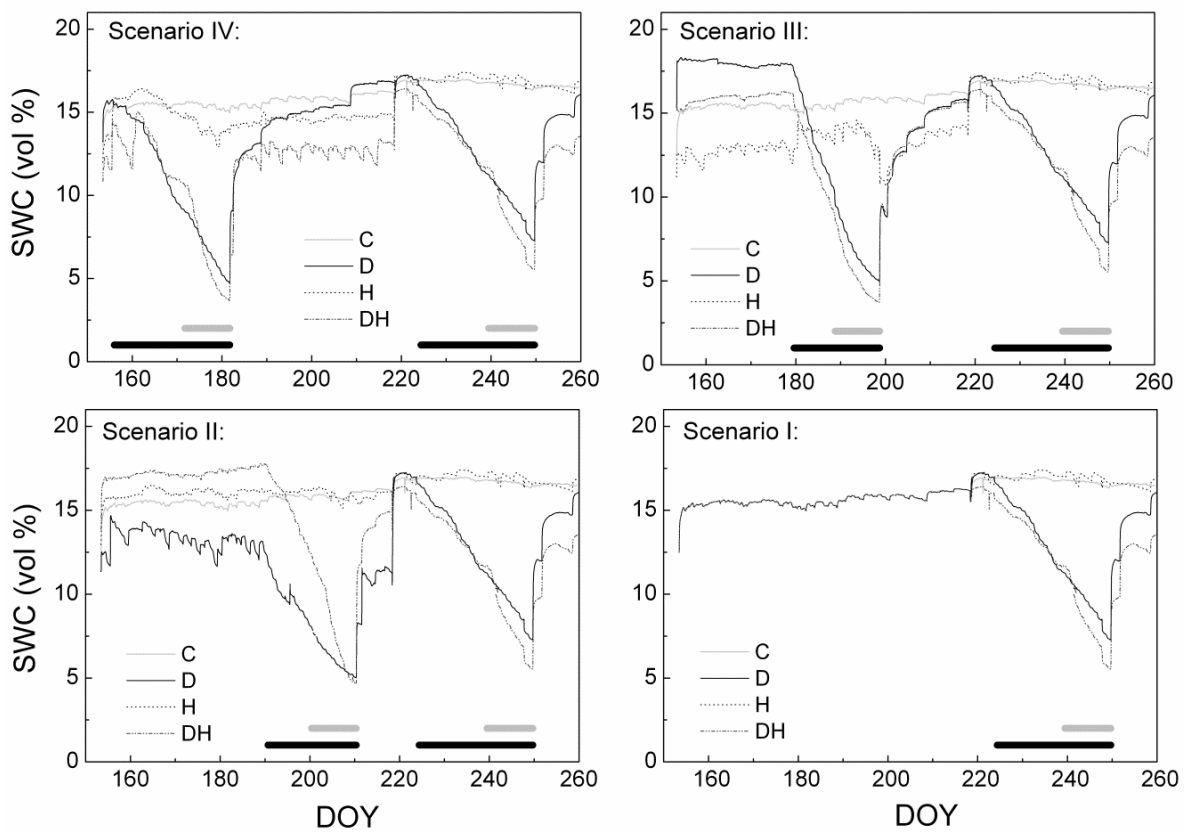

Fig. 1. Volumetric soil water content $(S W C)$ during different scenarios and treatments. $C=$ control, $D=$ drought, $H=$ heat, $D H=$ drought + heat. Bottom lines in each graph indicate timing of the climate events (black line $=$ timing of drought extreme, grey line $=$ timing of heat extreme). Scenario IV =42-day interval between subsequent events, scenario III = 25-day interval, scenario II $=14$-day interval, scenario $\mathrm{I}=$ single event.

vol \%, respectively. Air temperature sensors, shielded from direct radiation, recorded air temperature at the height of the canopy at half-hourly intervals.

\subsection{Intensity of climate extremes}

We simulated extremes with a return time of 50 years. The required length of the drought was determined by interpolation of return time data from the long-term climate database of the Royal Meteorological Institute of Belgium (records from 1880 to 2008) as the number of consecutive days with daily precipitation less than $1 \mathrm{~mm}$. For a $50 \mathrm{yr}$ drought extreme occurring in August, this yielded 25 days. The duration of the heat extremes was set to 10 days, which is a realistic length for the region (De Boeck et al., 2010). The maximum daily air temperatures $\left(T_{\max }\right)$ corresponding with heat extremes of that length were calculated, likewise by interpolation of return time data, using the same database. The 10-day heat extremes were applied towards the end of the rain-free period, in agreement with the meteorological characteristics of heat waves in western Europe (De Boeck et al., 2010).

The second extreme event, common to all scenarios, started on 12 August (day of year (DOY) 225) and lasted, as mentioned above, 25 days. The calculated mean target $T_{\max }$ of the heat wave applied during the last 10 days of this drought extreme was $28^{\circ} \mathrm{C}$. The calculated target $T_{\max }$ of the preceding heat waves was $30^{\circ} \mathrm{C}$ in each of the three scenarios. The preceding drought extreme of scenario IV started on
5 June (DOY 156), lasting 25 days. Since we studied the effect of the length of the recovery period between two consecutive extremes, we wanted the impact of the three preceding climate extremes on the plant assemblages to be as similar as possible. Therefore, during the first drought of scenario IV, we determined the soil water content that was reached at the time the heat wave was initiated (i.e. after 15 days). This soil water content then became the target drought level to be reached during the preceding drought extremes of scenarios III and II at which the heat extreme was initiated. In other words, the heat extreme was induced at a fixed soil water content independent of the number of days it took to reach this soil water content. As the target $T_{\max }$ was also the same during the three preceding heat extremes, the eventual intensity in all three preceding extremes was similar. Scenario III started on 28 June (DOY 179) with 19 days of no water supply, and scenario II on 9 July (DOY 190) followed by 20 days without water (see Table 1 and Fig. 1).

\subsection{Measurements}

The percentage of living leaves (leaf survival) was measured for each species by counting all leaves present and how many of these leaves were dead in five containers per treatment. Leaves were regarded dead if they were wilted and brown but still attached to the plant. These counts were made weekly before and after all climate extremes, but more frequently during the extremes. The percentage of green plants 
(whole-plant senescence) was determined in the same five containers per treatment (each container started with 10 individuals and all invading plants were removed).

Plant biomass was determined at the end of the growing season (2-3 November). Aboveground parts were cut from all plant assemblages and sorted per species. Belowground parts were sampled from 6 containers per treatment (but 18 for the control treatment) by carefully washing all soil from the container, leaving nothing but the roots. All biomass samples were weighed after drying at $70^{\circ} \mathrm{C}$. Three replicate samples of aboveground biomass for each species and of belowground biomass (all species combined) were analysed for nitrogen concentration with a carbon-nitrogen element analyser (NC-2100, Carlo Erba Instruments, Milan, Italy) after being ground and sieved over a $0.1 \mathrm{~mm}$ mesh.

\subsection{Statistical analysis}

All statistical tests were made using SAS (version 9.1, SAS Institute Inc., Cary, NC, USA). Biomass was analysed using two-way ANOVA with scenario (IV to I) and treatment (C, D, H and DH) as fixed factors for both the aboveground biomass per species and for the community biomass. The same analysis was used for the nitrogen stock and nitrogen concentration data. Normality of the data sets was tested with the Shapiro-Wilkinson test and post hoc tests were performed with the Tukey-Kramer correction. We analysed differences in the percentage of living leaves and green plants (per species and for the whole community) among treatments for each sampling date separately per scenario using one-way ANOVA (note that between-scenario comparisons on specific dates are not relevant because of the different exposure time associated with each scenario). Since these mortality data sets follow a binomial distribution and not a normal distribution, an ANOVA model for binomially distributed data was applied. Here, a chi-square test is used $\left(\chi^{2}\right)$ instead of the $F$ test in ANOVA for normally distributed data. The significance threshold was 0.05 .

\section{Results}

\subsection{Environmental conditions}

At the end of the first climate extremes of scenarios IV, III and II (i.e. DOY 181, 198 and 210), which had the same target $T_{\max }$ and the same target drought level, the soil water content was similar (Fig. 1). The D treatment reached SWC values around $5 \%$ in all three scenarios, while in the DH treatment SWC values ranged from $3.7 \%$ in scenario III to $4.7 \%$ in scenario II, thus almost dropping to wilting point $(3.7 \%$ in this soil). After re-watering, the soil water levels of the drought treatments (D and DH) fairly quickly reached field capacity again. During the second and common climate extreme, the mean SWC dropped to $7.4 \%$ in $\mathrm{D}$ and $5.6 \%$ in $\mathrm{DH}$.
Air temperatures at the height of the canopy during the heat extremes (same in $\mathrm{H}$ and $\mathrm{DH}$ ) reached a mean daily maximum of $32.6,34.5$ and $32.9^{\circ} \mathrm{C}$ for the first extremes of scenarios IV, III and II, respectively. During the common extreme, the daily mean maximum air temperature of the $\mathrm{H}$ and DH treatments equalled $30.2^{\circ} \mathrm{C}$, or $6.8^{\circ} \mathrm{C}$ above normal daily mean $T_{\max }$ (Table 1 ).

\subsection{Leaf survival}

The preceding climate extremes (i.e. the first extremes of scenarios IV, III and II) altered the percentage of living leaves compared to the controls (Fig. 2a). The first D treatment impaired leaf survival by $12.8 \%$ in scenario IV $\left(\chi^{2}=6.26, P=\right.$ $0.01)$ and $7.0 \%$ in scenario III $\left(\chi^{2}=3.90, P=0.048\right)$, while it increased leaf survival by $9.2 \%$ in scenario II $\left(\chi^{2}=4.65\right.$, $P=0.03)$. The first $\mathrm{H}$ treatment reduced the percentage of living leaves by $7.3 \%$ in scenario IV $\left(\chi^{2}=4.12, P=0.04\right)$, while it had no effect in the other scenarios. The loss of living leaves caused by the first DH extremes was more substantial and quite similar in all three scenarios: 24.1, 20.9 and $17.5 \%$ in scenarios IV, III and II, respectively $\left(\chi^{2}=9.88, P=\right.$ $0.002 ; \chi^{2}=19.92, P<0.0001$ and $\left.\chi^{2}=6.37, P=0.01\right)$. On the species level, the percentage of living leaves of $R$. acetosella was reduced by the first $\mathrm{D}$ extremes in scenarios IV and III (reduction of 23.3 and $10.1 \%$ in living leaves $\chi^{2}=7.12, P=0.0076$ and $\chi^{2}=6.71, P=0.04-$ in scenarios IV and III, respectively), but was increased in scenario II (by $15.6 \%, \chi^{2}=9.11, P=0.027$; Fig. 3a). Also B. perennis was affected by the $\mathrm{D}$ extremes, but only in scenario IV (reduction of $27.7 \%, \chi^{2}=6.47, P=0.01$; Fig. 3c). P. lanceolata, on the other hand, was never influenced by the D extremes (Fig. 3b), but was the only species that was affected by one of the preceding $\mathrm{H}$ extremes (in scenario IV; reduction of $9.8 \%, \chi^{2}=4.24, P=0.04$ ). While the sensitivity to $\mathrm{D}$ and $\mathrm{H}$ extremes varied among the species, all three species were more uniformly affected by the DH extremes. The first DH extremes of scenario IV, III and II resulted in a reduction of living leaves between 17 and $31 \%$ across all species and scenarios ( $P$ values all below 0.01$)$. In general, $B$. perennis experienced greater reductions in living leaves than the other species (Fig. 3c).

After re-watering, the percentage of living leaves increased again in all treatments that had suffered from losses. All three species had recovered to control values when the second, i.e the common, climate extreme was initiated (on DOY 222), and this in all scenarios (see Fig. 3a, b, c). During the second extreme, the DH treatment of scenario IV again caused losses in the percentage of living leaves of $P$. lanceolata $\left(\chi^{2}=6.47, P=0.011\right.$; Fig. $\left.3 \mathrm{~b}\right)$, but did not affect the two other species. In scenario III, the second events did not cause any negative effects. In contrast, the D extreme increased the percentage of living leaves of $R$. acetosella by $24 \%\left(\chi^{2}=5.86, P=0.016\right.$; Fig. 3a). This positive effect, however, was only temporary. During the DH extreme of sce- 

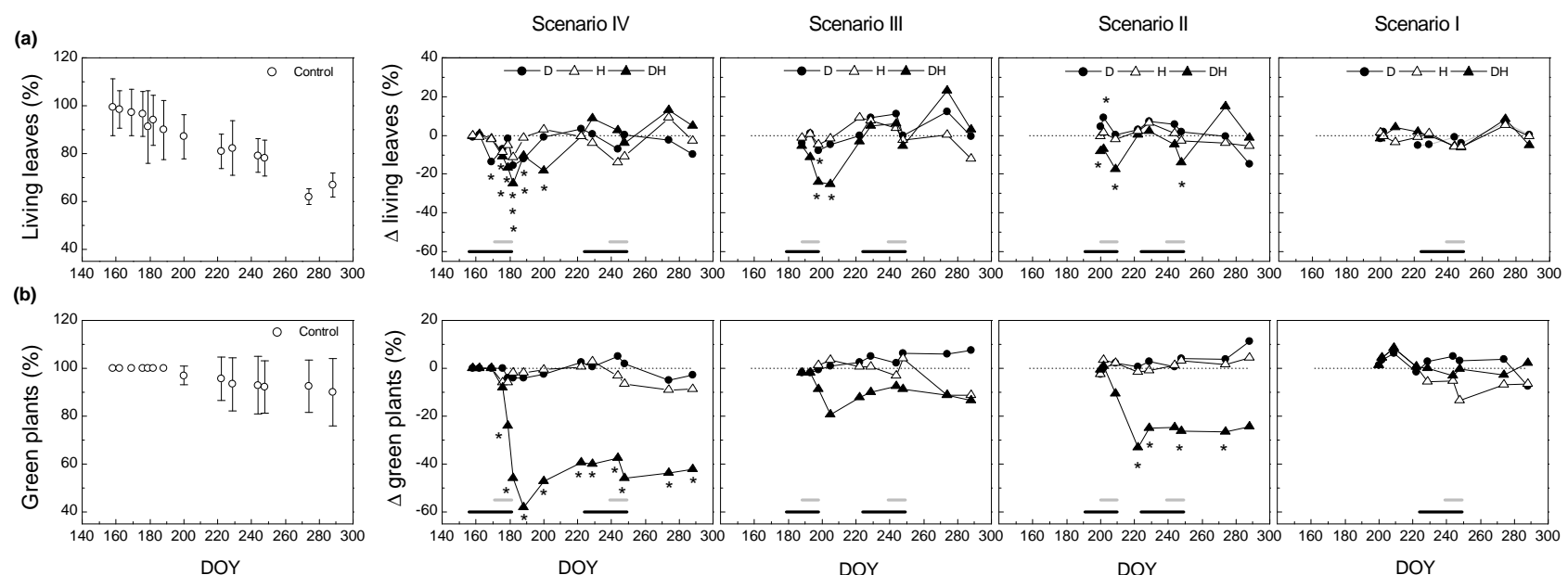

Fig. 2. Course of (a) the percentage of living leaves, and (b) the percentage of green plants for the whole plant community. Control values are given (left panel) and the difference between the controls and the treatments during the different scenarios. Standard errors are displayed for the controls but are not shown for the other treatments for improved clarity. $\mathrm{D}=$ drought (closed circles), $\mathrm{H}=$ heat (open triangles), $\mathrm{DH}=$ drought + heat (closed triangles). Bottom lines in each graph indicate timing of the climate events $(\mathrm{black}$ line $=$ drought, grey line $=$ heat wave). Asterisks, arranged in the same vertical order as the points, indicate significant differences $(P<0.05)$ between treatments and control on that day. DOY = day of year.
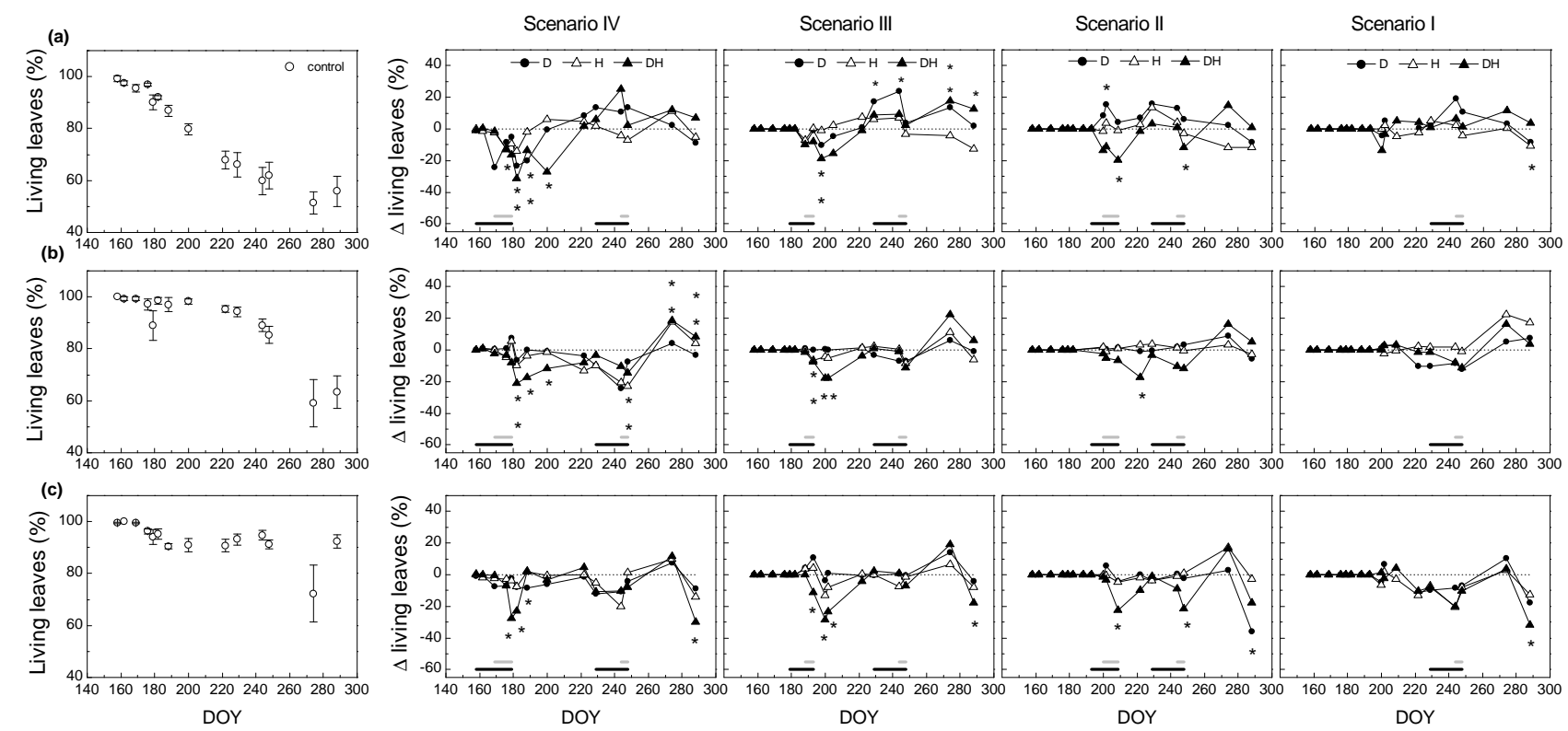

Fig. 3. Course of the percentage of living leaves, per species, for (a) Rumex acetosella, (b) Plantago lanceolata and (c) Bellis perennis. Control values are given (left panel) and the difference between the controls and the treatments during the different scenarios. Standard errors are displayed for the controls but are not shown for the other treatments for improved clarity. $\mathrm{D}=$ drought (closed circles), $\mathrm{H}=$ heat (open triangles), $\mathrm{DH}=$ drought + heat (closed triangles). Bottom lines in each graph indicate timing of the climate events (black line $=$ drought, grey line $=$ heat wave). Asterisks, arranged in the same vertical order as the points, indicate significant differences $(P<0.05)$ between treatments and control on that day. DOY = day of year.

nario II, the percentage of living leaves of both $R$. acetosella and $B$. perennis was again negatively affected $\left(\chi^{2}=3.78\right.$, $\left.P=0.049 ; \chi^{2}=5.75, P=0.017\right)$. On the community level, leaf losses were only visible in the $\mathrm{DH}$ treatment of scenario II (17\% decline, $\chi^{2}=7.55, P=0.006$ ) (Fig. $\left.2 \mathrm{a}\right)$. When the second climate extreme was applied without any preceding extremes (scenario I), no leaf losses were observed (Figs. 2a and $3 a, b, c)$. Note that by the end of the growing season, the $\mathrm{H}$ and DH treatments of scenario IV had increased the percentage of living leaves of $P$. lanceolata $\left(\chi^{2}=10.43, P=\right.$ 

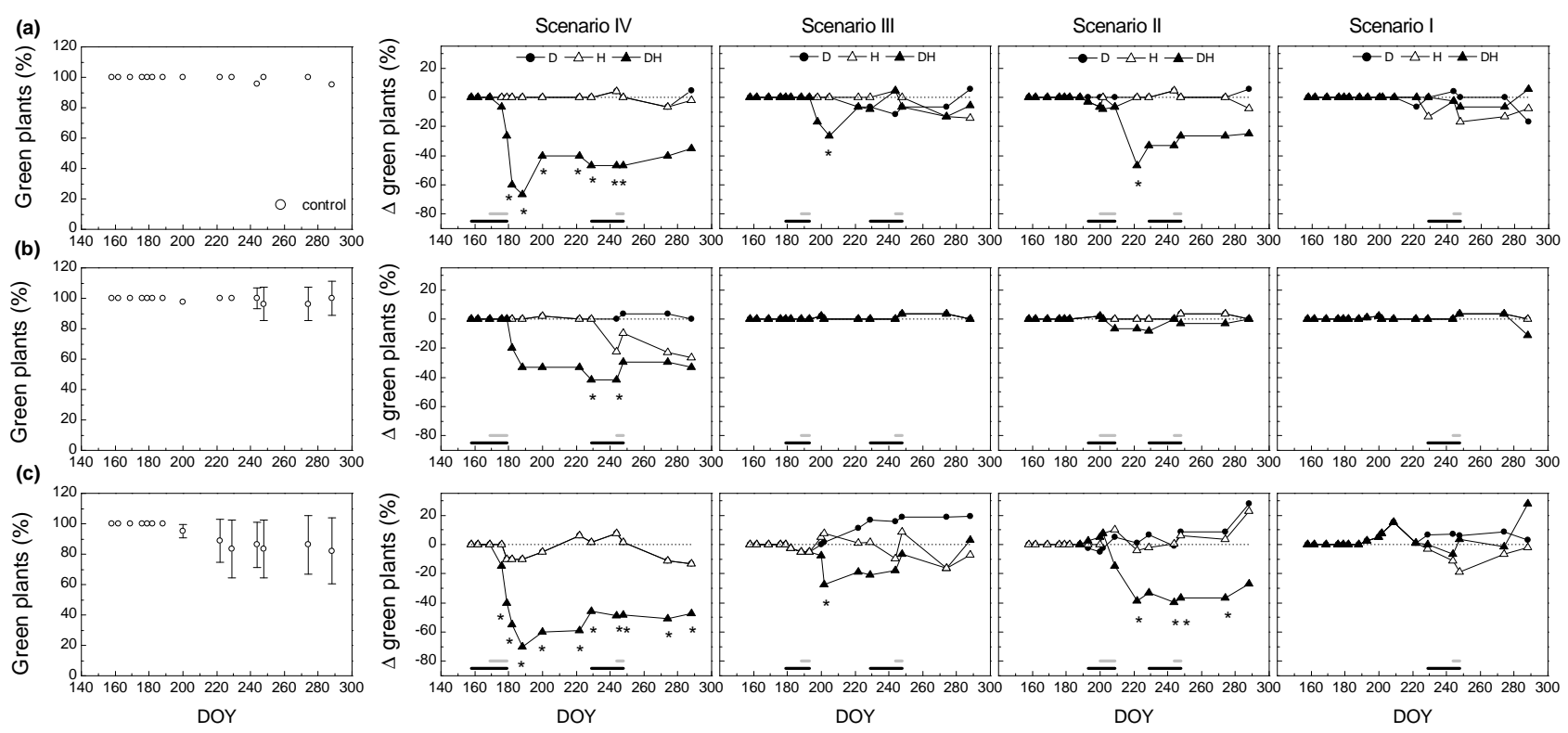

Fig. 4. Course of the percentage of green plants, per species, for (a) Rumex acetosella, (b) Plantago lanceolata and (c) Bellis perennis. Control values are given (left panel) and the difference between the controls and the treatments during the different scenarios. Standard errors are displayed for the controls but are not shown for the other treatments for improved clarity. $\mathrm{D}=$ drought (closed circles), $\mathrm{H}=$ heat (open triangles), $\mathrm{DH}=$ drought + heat (closed triangles). Bottom lines in each graph indicate timing of the climate events (black line $=$ drought, grey line $=$ heat wave). Asterisks, arranged in the same vertical order as the points, indicate significant differences $(P<0.05)$ between treatments and control on that day. DOY = day of year.

0.0012 and $\chi^{2}=6.56, P=0.010$; Fig. $3 b$ ), but not in the other scenarios. An increased percentage of living leaves at the end of the growing season also occurred in $R$. acetosella after the DH treatment, but only in scenario III $\left(\chi^{2}=4.77\right.$, $P=0.035$; Fig. 3a).

\subsection{Whole-plant senescence}

The impact of the preceding events on whole-plant senescence differed among the scenarios, notably in DH. On the community level, the greatest reduction in green plants caused by the preceding DH treatments reached $58 \%$ in scenario IV $\left(\chi^{2}=18.58, P<0.0001\right)$ and $30 \%$ in scenario II $\left(\chi^{2}=7.12, P=0.008\right)$, whereas no significant effect was observed in scenario III (Fig. 2b). Note that the percentage of green plants slightly increased again after the DH extreme in scenarios IV and II, owing to senesced plants that resprouted. The other climate treatments (D and $\mathrm{H}$ ) never affected wholeplant senescence. Compared to the other two species, $P$. lanceolata was the least sensitive to the extreme events. The events of scenarios III and II had no effect on the wholeplant senescence of $P$. lanceolata, and only the preceding DH extreme of scenario IV caused a (albeit statistically nonsignificant) $33.3 \%$ decrease in green plants (Fig. $4 \mathrm{~b}$ ). $R$. acetosella and $B$. perennis experienced decreases in green plants of 66.6 and $70 \%$ during the first DH extremes of scenario IV $\left(\chi^{2}=8.61, P=0.003\right.$ and $\left.\chi^{2}=9.91, P=0.016\right)$, 26.6 and $27.5 \%$ during scenario III $\left(\chi^{2}=2.67, P=0.045\right.$ and $\left.\chi^{2}=2.74, P=0.043\right)$ and 46.7 and $38.8 \%$ during scenario II $\left(\chi^{2}=3.15, P=0.017\right.$ and $\left.\chi^{2}=2.48, P=0.027\right)$ (Fig. 4a, c). The second DH extreme had no or only a limited impact. As with leaf mortality, the second climate extreme had no effect on whole-plant senescence when applied without preceding extremes (scenario I, Figs. $2 b$ and $4 a, b, c)$.

The responses of leaf survival and whole-plant senescence described above allow us to address our central question, which was whether herbaceous vegetation becomes more vulnerable or more resistant to a climate extreme after having faced an earlier one, and whether this effect would be influenced by the interval between them. In Fig. 5a and b, we therefore plot the influence on whole-plant senescence and leaf survival caused by the second extreme only (i.e. the difference in the percentage of living leaves or green plants before and after the second extreme) as a function of the number of days since the end of the first extreme. The second extreme had no effect on community plant senescence in any of the scenarios (Fig. 5a). When expressed as leaf survival, however, resistance to the second extreme was negatively affected by previous events, but only for DH and under the scenario with the shortest recovery period (scenario II, Fig. 5b; $\chi^{2}=7.55, P=0.006$ ). This decrease was visible in both $R$. acetosella and B. perennis (see Fig. 3a,c). Previous exposures with a longer recovery period (scenarios IV and III) did not change the resistance of leaf survival to the second extreme. 
Table 2. Mean tissue nitrogen concentration and standard errors for each species and for the roots in all scenarios. $\mathrm{C}=\mathrm{control}, \mathrm{D}=\mathrm{drought}$, $\mathrm{H}=$ heat, $\mathrm{DH}=$ drought + heat. Scenario IV = 42-day interval between subsequent events, scenario III $=25$-day interval, scenario II $=14$ day interval, scenario $\mathrm{I}=$ single event. Asterisks indicate significant differences $(P<0.05)$ between treatment and control.

\begin{tabular}{llrrrrrrrr}
\hline & & \multicolumn{2}{c}{ Scenario IV } & \multicolumn{2}{c}{ Scenario III } & \multicolumn{2}{c}{ Scenario II } & \multicolumn{2}{c}{ Scenario I } \\
& & mean & SE & mean & SE & mean & SE & mean & SE \\
\hline P. lanceolata & C & 1.1 & 0.03 & 1.1 & 0.03 & 1.1 & 0.03 & 1.1 & 0.03 \\
& D & 1.11 & 0.03 & $1.22^{*}$ & 0.003 & 1.14 & 0.003 & 1.19 & 0.01 \\
& $\mathrm{H}$ & 1.05 & 0.01 & 1.06 & 0.01 & $0.92^{*}$ & 0.01 & 0.99 & 0.01 \\
& $\mathrm{DH}$ & $1.23^{*}$ & 0.01 & 1.01 & 0.002 & 1.2 & 0.01 & $1.34^{*}$ & 0.06 \\
\hline R. acetosella & $\mathrm{C}$ & 0.8 & 0.02 & 0.8 & 0.02 & 0.8 & 0.02 & 0.8 & 0.02 \\
& $\mathrm{D}$ & 0.56 & 0.005 & 0.9 & 0.05 & 0.85 & 0.02 & 0.74 & 0.003 \\
& $\mathrm{H}$ & 0.81 & 0.03 & 0.78 & 0.06 & 0.82 & 0.01 & 0.77 & 0.01 \\
& $\mathrm{DH}$ & $1.02^{*}$ & 0.02 & $1.12^{*}$ & 0.01 & $1.34 *$ & 0.02 & $0.46^{*}$ & 0.005 \\
\hline \multirow{2}{*}{ B. perennis } & $\mathrm{C}$ & 1.16 & 0.07 & 1.16 & 0.07 & 1.16 & 0.07 & 1.16 & 0.07 \\
& $\mathrm{D}$ & 1.11 & 0.005 & 1.29 & 0.03 & 0.95 & 0.01 & 1.18 & 0.001 \\
& $\mathrm{H}$ & 1.13 & 0.01 & 0.86 & 0.13 & 0.92 & 0.03 & 0.92 & 0.05 \\
& $\mathrm{DH}$ & 1.36 & 0.01 & 0.89 & 0.01 & 1.15 & 0.02 & 1.17 & 0.01 \\
\hline Roots & $\mathrm{C}$ & 0.47 & 0.02 & 0.47 & 0.02 & 0.47 & 0.02 & 0.47 & 0.02 \\
& $\mathrm{D}$ & 0.45 & 0.04 & 0.45 & 0.02 & 0.49 & 0.02 & 0.49 & 0.03 \\
& $\mathrm{H}$ & 0.52 & 0.03 & 0.49 & 0.02 & 0.51 & 0.03 & 0.51 & 0.06 \\
& $\mathrm{DH}$ & 0.51 & 0.04 & 0.58 & 0.02 & 0.51 & 0.03 & 0.59 & 0.08 \\
\hline
\end{tabular}

\subsection{End-of-season biomass}

Relative to the control treatment, the two heated treatments $(\mathrm{H}$ and $\mathrm{DH})$ increased the community aboveground biomass by the end of the growing season in all scenarios with two recurrent extremes (Fig. $6 \mathrm{a}-F=24.78, P<0.0001$; $F=13.36, P=0.0006$; and $F=11.81, P=0.001$ for scenarios IV, III and II, respectively). There were no differences among the three scenarios with recurrent climate extremes. In scenario IV, the DH treatment had increased the biomass of both $P$. lanceolata and $R$. acetosella $(F=4.98$, $P=0.0035$ and $F=3.27, P=0.026$ ), while the $\mathrm{H}$ treatment had increased the biomass of $B$. perennis $(F=9.51$, $P<0.0001$ ) (Fig. 6a). Increases in community biomass in the other scenarios with two recurrent extremes (III and II) were uniquely caused by increases in the biomass of $P$. lanceolata $(F=7.83, P<0.0001$ and $F=7.32, P=0.0003)$. In the plant assemblages exposed only to the single extreme (scenario I), an increased aboveground biomass was likewise observed, but only in DH $(F=2.84, P=0.045)$. Also here, this was because of an increase in the biomass of $P$. lanceolata $(F=2.79, P=0.043)$ (Fig. 6a).

While the belowground (Fig. 6b) and the total (aboveground + belowground) biomass were similar in all treatments, biomass partitioning towards the aboveground parts was enhanced (as indicated by the lower root-to-shoot ratios in Fig. 6c) in the DH treatments of scenarios IV and II $(F=5.13, P=0.003$ and $F=4.81, P=0.01)$. The DH treatment of scenario III and the $\mathrm{H}$ treatments of all scenarios showed a similar (albeit statistically nonsignificant) trend.

\subsection{Nitrogen stock and nitrogen concentration}

In agreement with the total biomass, the total nitrogen stock and root nitrogen stock did not differ among treatments (Fig. 7b). The aboveground parts, however, showed a higher nitrogen stock in the DH treatment of scenario III $(F=3.50$, $P=0.02$ ), and this trend was visible in the DH treatments of the other scenarios as well (Fig. 7a). On the species level, the only difference in nitrogen stock, compared to the controls, was found in $R$. acetosella in the DH treatment of scenario IV, where it was increased $(F=4.54, P=0.02)$ (Fig. 7a). The tissue nitrogen concentration of $R$. acetosella was higher than the controls in the DH treatments in scenarios IV, III and II $(F=6.68, P<0.0001 ; F=7.38, P<$ 0.0001 ; and $F=17.11, P<0.0001)$, but was lower in scenario I $(F=11.89, P<0.0001)$ (Table 2$)$. The nitrogen concentration of $P$. lanceolata was increased in the DH treatment of scenarios IV and I $(F=3.91, P=0.032$ and $F=12.05$, $P=0.0004)$ and the D treatment of scenario III $(F=5.53$, $P=0.010$ ), but was decreased in the $\mathrm{H}$ treatment of scenario II $(F=9.82, P=0.0010)$. The extreme events never influenced the tissue nitrogen concentration of $B$. perennis nor the nitrogen concentration in the roots (Table 2). 

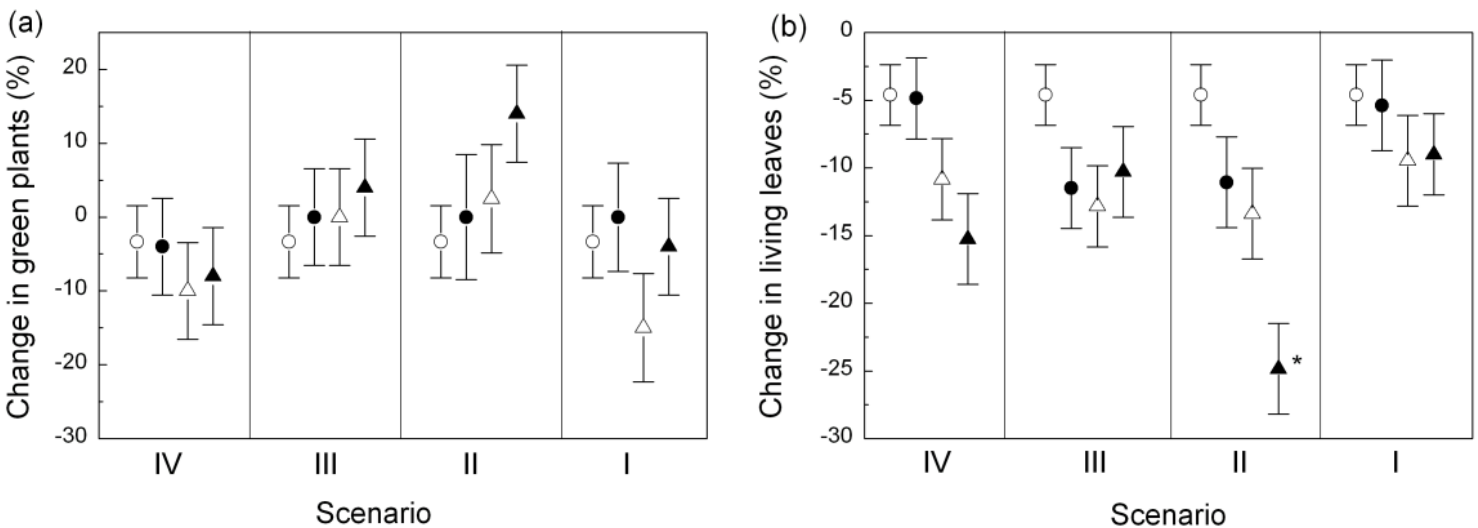

Fig. 5. Influence of the second extreme on (a) whole-plant senescence and (b) leaf survival per scenario. Control=open circles, drought $=$ closed circles, heat $=$ open triangles, drought + heat $=$ closed triangles. Asterisks next to symbols indicate significant differences $(P<0.05)$ between treatment and control. Scenario IV $=42$-day interval between subsequent events, scenario III $=25$-day interval, scenario $\mathrm{II}=14$-day interval, scenario $\mathrm{I}=$ single event.

\section{Discussion}

\subsection{Effects of single extremes}

In contrast to our expectations, drought-only extremes (i.e. drought not combined with heat) did not influence end-ofseason biomass or whole-plant senescence, and had only limited effects on leaf survival. The number of days without water input and the timing of our preceding extremes were similar to those applied in the summer drought extreme by De Boeck et al. (2011), which was carried out with the same experimental set-up. Unlike this study, De Boeck et al. (2011) observed a strong negative impact of the drought extreme on end-of-season biomass. The fact that the same drought duration in the same period can lead to very different productivity responses is highly intriguing. As there were no noteworthy differences in air temperature between both these experiments (that could have induced substantial differences in vapour pressure deficit or soil drying), this strengthens our belief that this difference is mainly attributable to the different plant combinations used. The plant assemblages exposed to climate extremes by De Boeck et al. (2011) were similar to the ones used here, except that we replaced Trifolium repens by $B$. perennis. Apparently, substituting one species created a substantial difference in the drought response of the assemblage. In our current experiment without the fastgrowing legume $T$. repens, all assemblages produced much less biomass, and, as a consequence, likely consumed much less water. We assume that greater water consumption in the study by De Boeck et al. (2011) explains their much higher vulnerability to drought. This explanation is in line with other experiments that observed a stronger negative effect of drought on plant communities containing greater nitrogen stocks, either through the presence of legumes (Pfisterer and Schmid, 2002; Kreyling et al., 2008) or through manually added nitrogen (Gordon et al., 1999; Keller, 2005), as these communities were more productive. Furthermore, other studies have also related ecosystem productivity to drought sensitivity (van Ruijven and Berendse, 2010; Van Peer et al., 2001, 2004; Wang et al., 2007). This implies that plant community composition and/or ecosystem fertility are essential predictors for the response of a community to drought extremes. Furthermore, this is a good example of the fact that a statistically extreme event either can or can not trigger an extreme response, depending in our case on the sensitivity of the plants used and on the water consumption of the community.

We did not expect negative effects of heat-only extremes, as plants would be able to cool themselves when supplied with ample water. Our experiment indeed revealed no detrimental influence of heat (except very occasionally in scenario IV), and - in contrast - even an increased aboveground biomass. When heat was combined with drought, leaf and plant survival declined strongly, yet aboveground biomass at the end of the season was also greater. The heated and especially the combined treatments leaned towards a lower rootto-shoot ratio than the non-heated treatments ( $\mathrm{C}$ and $\mathrm{D})$. This shift in biomass and also nitrogen allocation from roots to shoots in the heated treatments suggests a reduced investment in the search for nutrients or a lower seasonal retranslocation of nitrogen from already senescing leaves to storage organs (Heckathorn and Delucia, 1996). The heated treatments may thus have had more easy access to soil nutrients, through accelerated nutrient mineralization under heating (Emmett et al., 2004; Rustad et al., 2001) or through decreased nutrient competition as a consequence of mortality of neighbouring plants. Higher oxygen levels in the drier soils of DH compared to $\mathrm{H}$ may have further stimulated mineralization in the deeper soil. This may explain why treatment $\mathrm{H}$ and especially DH tended to maintain relatively more biomass and nitrogen in the aboveground parts compared to $\mathrm{C}$ and $\mathrm{D}$. The increased 


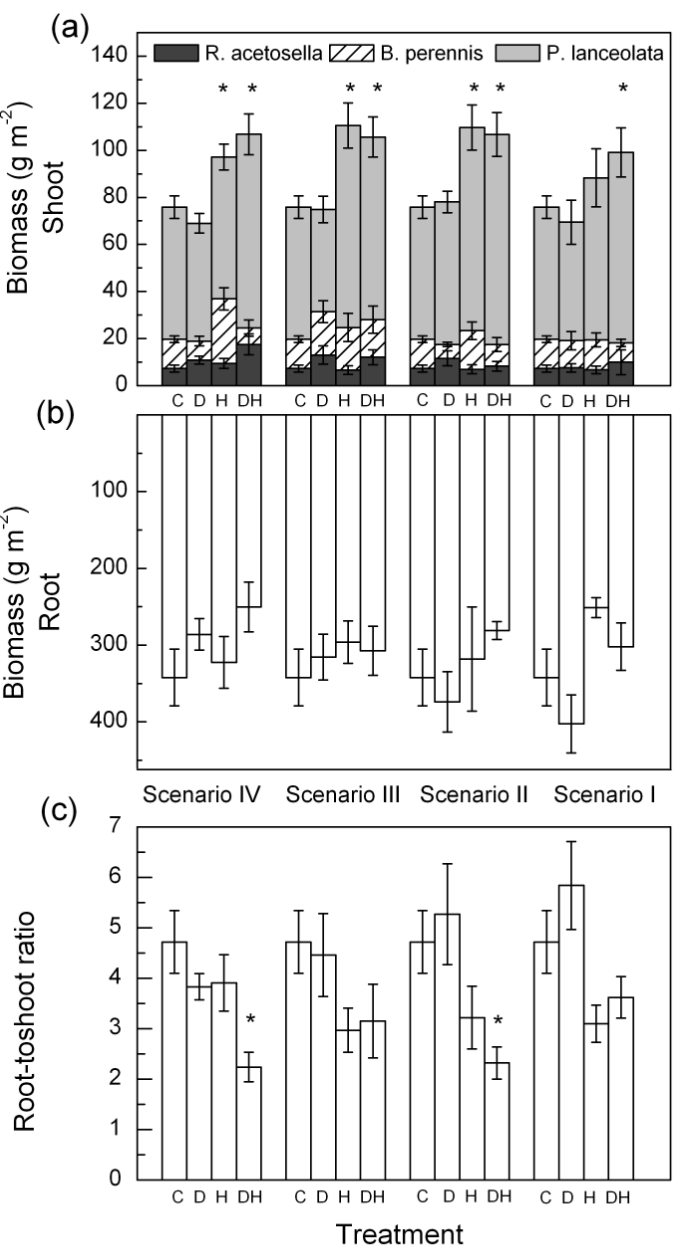

Fig. 6. Mean values and standard errors of the end-of-season (a) aboveground biomass, (b) belowground biomass and (c) root-toshoot ratios, per scenario and treatment. $\mathrm{C}=$ control, $\mathrm{D}=$ drought, $\mathrm{H}=$ heat, $\mathrm{DH}=$ drought + heat. Asterisks indicate significant differences between treatment and control on the community level $(P<0.05)$. For differences on the species level, please refer to the text. Scenario IV $=42$-day interval between subsequent events, scenario $\mathrm{III}=25$-day interval, scenario $\mathrm{II}=14$-day interval, scenario $\mathrm{I}=$ single event.

tissue nitrogen concentrations in $R$. acetosella and P. lanceolata in the DH treatments support this theory.

Our results show varying impacts of the preceding single extremes on whole-plant senescence and leaf survival depending on the scenario, in spite of the similarity in soil water content and daily maximal temperature. The first extreme of scenario III did not induce any plant senescence, contrasting with the first extremes of scenarios IV and II, where the percentage of green plants (in the DH treatments) was reduced by 58 and $30 \%$, respectively. These differences can be partly explained by differences in the soil water content among the events. Although the soil water content was around the wilting point during all events and differences
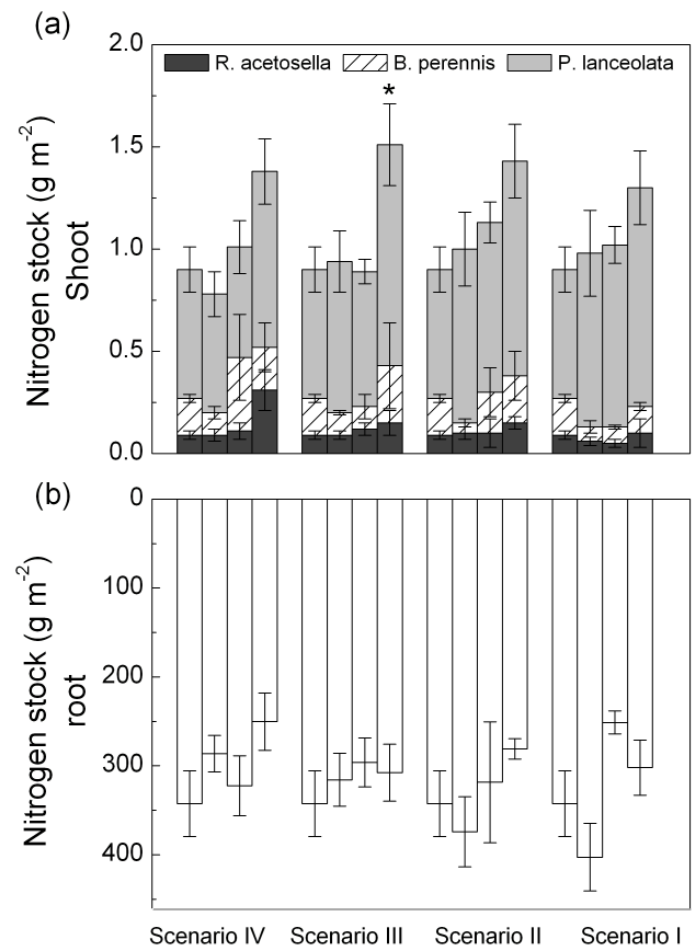

Fig. 7. Mean end-of-season (a) aboveground and (b) belowground nitrogen stock, per scenario and treatment. $\mathrm{C}=$ control, $\mathrm{D}=$ drought, $\mathrm{H}=$ heat, $\mathrm{DH}=$ drought + heat. Asterisks above bars indicate significant differences between treatment and control on the community level $(P<0.05)$. For differences on the species level, please refer to the text. Scenario IV $=42$-day interval between subsequent events, scenario III $=25$-day interval, scenario II $=14$ day interval, scenario $\mathrm{I}=$ single event.

among events were very small (maximum 1 vol \%), it makes a huge difference for the plant response whether or not a specific threshold is exceeded. Furthermore, the sensitivity to drought conditions can differ depending on the developmental stage of the plants. For example, Gupta et al. (2001) reported that the capacity of wheat plants to cool their leaves was lower in the anthesis stage compared to the boot stage earlier in the season, which can lead to reduced yield when drought occurs at that stage. Several studies found that when drought occurred during reproductive growth stages, yield was more strongly affected compared to drought conditions occurring during the vegetative growth stages (Boonjung and Fukai, 1996; Cakir, 2004; Mingeau et al., 2001). It is, furthermore, possible that plants had not yet fully developed their root system during the earliest event (scenario IV), making them more vulnerable to drought conditions. A higher amount of leaf area and thus evaporative surface later in the season might explain why mortality in the last preceding event (scenario II) was high as well. In contrast to the above-mentioned studies, however, no yield losses in terms of biomass were observed in our study for any of the three 
species. The differences in mortality were not present anymore in the end-of-season biomass, indicating that remaining plants profited from decreased competition for resources and exhibited compensatory growth.

\subsection{Single versus recurrent extremes and effect of recovery time}

When facing recurrent extremes, the state of the system when entering the second event will be a factor determining the outcome. This state is determined by the system's resistance and resilience to the first event, and the elapsed time since that first event. Slow-growing, long-lived systems that are not very resilient (e.g. forests) will face a slow recovery, and may be more likely to experience the cumulative impact of multiple extremes in the course of their lifespan. Grasslands, however, generally exhibit fast recovery (Brilli et al., 2011; Walter et al., 2011; Zavalloni et al., 2008), which we also observed in this study. The recovery period between recurrent extreme events in grasslands would therefore be most important in the case of relatively short interval periods, as recovery would then still be incomplete. Our results indeed show that leaf mortality at the end of the second extreme, which was limited to the DH treatment, was induced only when the recovery period was 14 days. Strikingly, this occurred in spite of apparent complete recovery in living leaves before the initiation of that second event. The fact that a reduced resistance caused by the first event was still present but no longer detectable in the form of leaf mortality suggests that physiological or molecular processes may still have been affected. However, this phenomenon did not persist very long, as the scenarios with a longer interval period did not show such a reduced resistance.

\section{Conclusions}

Our results show that when experimental temperate herbaceous assemblages were exposed to an extreme climatic event, their resistance to a subsequent event, in terms of leaf survival, is reduced only when the recovery period is relatively short (14 days for the assemblages studied here) and not when it is longer. Moreover, only combinations of extreme heat and drought suffered from loss of resistance, and the memory effects of previous events occurred even though recovery seemed complete and leaf damage was no longer detectable. End-of-season biomass was independent of the recovery period and of the number of applied events despite substantial plant loss in some of the treatments. In the assemblages exposed to the heated and combined heat and drought extremes, aboveground biomass was even increased, indicating that indirect effects of heating compensated for the short-term negative effects.
Supplementary material related to this article is available online at http://www.biogeosciences.net/11/109/ 2014/bg-11-109-2014-supplement.pdf.

Acknowledgements. H. J. De Boeck is a post-doctoral research associate of the Fund for Scientific Research, Flanders. We thank Marc Wellens and Fred Kockelbergh for technical assistance.

Edited by: P. Stoy

\section{References}

Boonjung, H. and Fukai, S.: Effects of soil water deficit at different growth stages on rice growth and yield under upland conditions, 2. Phenology, biomass production and yield, Field Crop. Res., 48, 47-55, 1996.

Bréda, N., Huc, R., Granier, A., and Dreyer, E.: Temperate forest trees and stands under severe drought: a review of ecophysiological responses, adaptation processes and long-term consequences, Ann. For. Sci., 63, 625-644, 2006.

Breshears, D. D., Cobb, N. S., Rich, P. M., Price, K. P., Allen, C. D., Balice, R. G., Romme, W. H., Kastens, J. H., Floyd, M. L., Belnap, J., Anderson, J. J., Myers, O. B., and Meyer, C. W.: Regional vegetation die-off in response to global-change-type drought, $\mathrm{P}$. Natl. Acad. Sci. USA, 102, 15144-15148, 2005.

Brilli, F., Hortnagl, L., Hammerle, A., Haslwanter, A., Hansel, A., Loreto, F., and Wohlfahrt, G.: Leaf and ecosystem response to soil water availability in mountain grasslands, Agric. For. Meteorol., 151, 1731-1740, 2011.

Bruce, T. J. A., Matthes, M. C., Napier, J. A., and Pickett, J. A.: Stressful "memories" of plants: Evidence and possible mechanisms, Plant Sci., 173, 603-608, 2007.

Cakir, R.: Effect of water stress at different development stages on vegetative and reproductive growth of corn, Field Crop. Res., 89, 1-16, 2004.

Ciais, P., Reichstein, M., Viovy, N., Granier, A., Ogee, J., Allard, V., Aubinet, M., Buchmann, N., Bernhofer, C., Carrara, A., Chevallier, F., De Noblet, N., Friend, A. D., Friedlingstein, P., Grunwald, T., Heinesch, B., Keronen, P., Knohl, A., Krinner, G., Loustau, D., Manca, G., Matteucci, G., Miglietta, F., Ourcival, J. M., Papale, D., Pilegaard, K., Rambal, S., Seufert, G., Soussana, J. F., Sanz, M. J., Schulze, E. D., Vesala, T., and Valentini, R.: Europewide reduction in primary productivity caused by the heat and drought in 2003, Nature, 437, 529-533, 2005.

Craine, J. M., Nippert, J. B., Elmore, A. J., Skibbe, A. M., Hutchinson, S. L., and Brunsell, N. A.: Timing of climate variability and grassland productivity, P. Natl. Acad. Sci. USA, 109, 3401-3405, 2012.

De Boeck, H. J., Dreesen, F. E., Janssens, I. A., and Nijs, I.: Climatic characteristics of heat waves and their simulation in plant experiments, Global Change Biol., 16, 1992-2000, 2010.

De Boeck, H. J., Dreesen, F. E., Janssens, I. A., and Nijs, I.: Wholesystem responses of experimental plant communities to climate extremes imposed in different seasons, New Phytol., 189, 806$817,2011$. 
Dreesen, F. E., De Boeck, H. J., Janssens, I. A., and Nijs, I.: Summer heat and drought extremes trigger unexpected changes in productivity of a temperate annual/biannual plant community, Environ. Exp. Bot., 79, 21-30, 2012.

Emmett, B. A., Beier, C., Estiarte, M., Tietema, A., Kristensen, H. L., Williams, D., Peñuelas, J., Schmidt, I., and Sowerby, A.: The response of soil processes to climate change: results from manipulation studies of shrublands across an environmental gradient, Ecosystems, 7, 625-637, 2004.

Fischer, E. M. and Schär, C.: Consistent geographical patterns of changes in high-impact European heatwaves, Nat. Geosci., 3, 398-403, 2010.

Galiano, L., Martinez-Vilalta, J., and Lloret, F.: Carbon reserves and canopy defoliation determine the recovery of Scots pine $4 \mathrm{yr}$ after a drought episode, New Phytol., 190, 750-759, 2011.

Gallé, A., Florez-Sarasa, I., El Aououad, H., and Flexas, J.: The Mediterranean evergreen Quercus ilex and the semi-deciduous Cistus albidus differ in their leaf gas exchange regulation and acclimation to repeated drought and re-watering cycles, J. Exp. Bot., 62, 5207-5216, 2011.

Gordon, C., Woodin, S. J., Alexander, I. J., and Mullins, C. E.: Effects of increased temperature, drought and nitrogen supply on two upland perennials of contrasting functional type: Calluna vulgaris and Pteridium aquilinum, New Phytol., 142, 243-258, 1999.

Guarnaschelli, A. B., Prystupa, P., and Lemcoff, J. H.: Drought conditioning improves water status, stomatal conductance and survival of Eucalyptus globulus subsp bicostata seedlings, Ann. For. Sci., 63, 941-950, 2006.

Gupta, N. K., Gupta, S., and Kumar, A.: Effect of water stress on physiological attributes and their relationship with growth and yield of wheat cultivars at different stages, Journal of Agronomy and Crop Science-Zeitschrift Fur Acker Und Pflanzenbau, 186, 55-62, 2001.

Heckathorn, S. A. and Delucia, E. H.: Retranslocation of shoot nitrogen to rhizomes and roots in prairie grasses may limit loss of $\mathrm{N}$ to grazing and fire during drought, Funct. Ecol., 10, 396-400, 1996.

IPCC: Managing the Risks of Extreme Events and Disasters to Advance Climate Change Adaptation, A Special Report of Working Groups I and II of the Intergovernmental Panel on Climate Change in, edited by: Field, C. B., Barros, V., Stocker, T. F., Qin, D., Dokken, D. J., Ebi, K. L., Mastrandrea, M. D., Mach, K. J., Plattner, G.-K., Allen, S. K., Tignor, M., and Midgley, P. M., Cambridge University Press, Cambridge, UK and New York, USA, p. 582, 2012.

Keller, M.: Deficit irrigation and vine mineral nutrition, Am. J. Enol. Vitic., 56, 267-283, 2005.

Kreyling, J., Wenigmann, M., Beierkuhnlein, C., and Jentsch, A.: Effects of extreme weather events on plant productivity and tissue die-back are modified by community composition, Ecosystems, 11, 752-763, 2008.

Leuzinger, S., Zotz, G., Asshoff, R., and Körner, C.: Responses of deciduous forest trees to severe drought in Central Europe, Tree Physiol., 25, 641-650, 2005.

Liu, C. C., Liu, Y. G., Guo, K., Zheng, Y. R., Li, G. Q., Yu, L. F., and Yang, R.: Influence of drought intensity on the response of six woody karst species subjected to successive cycles of drought and rewatering, Physiol. Plantarum, 139, 39-54, 2010.
Lloret, F., Siscart, D., and Dalmases, C.: Canopy recovery after drought dieback in holm-oak Mediterranean forests of Catalonia (NE Spain), Global Change Biol., 10, 2092-2099, 2004.

Luo, Y. Y., Zhao, X. Y., Zhou, R. L., Zuo, X. A., Zhang, J. H., and Li, Y. Q.: Physiological acclimation of two psammophytes to repeated soil drought and rewatering, Acta Physiol. Plant., 33, 79-91, 2011.

Marchand, F. L., Kockelbergh, F., van de Vijver, B., Beyens, L., and Nijs, I.: Are heat and cold resistance of arctic species affected by successive extreme temperature events?, New Phytol., 170, 291300, 2006.

Meehl, G. A., Karl, T., Easterling, D. R., Changnon, S., Pielke, R., Changnon, D., Evans, J., Groisman, P. Y., Knutson, T. R., Kunkel, K. E., Mearns, L. O., Parmesan, C., Pulwarty, R., Root, T., Sylves, R. T., Whetton, P., and Zwiers, F.: An introduction to trends in extreme weather and climate events: observations, socioeconomic impacts, terrestrial ecological impacts, and model projections, B. Am. Meteorol. Soc., 81, 413-416, 2000.

Mingeau, M., Perrier, C., and Ameglio, T.: Evidence of droughtsensitive periods from flowering to maturity on highbush blueberry, Scientia Horticulturae, 89, 23-40, 2001.

Miyashita, K., Tanakamaru, S., Maitani, T., and Kimura, K.: Recovery responses of photosynthesis, transpiration, and stomatal conductance in kidney bean following drought stress, Environ. Exp. Bot., 53, 205-214, 2005.

Peñuelas, J., Prieto, P., Beier, C., Cesaraccio, C., de Angelis, P., de Dato, G., Emmett, B. A., Estiarte, M., Garadnai, J., Gorissen, A., Lang, E. K., Kroel-Dulay, G., Llorens, L., Pellizzaro, G., RiisNielsen, T., Schmidt, I. K., Sirca, C., Sowerby, A., Spano, D., and Tietema, A.: Response of plant species richness and primary productivity in shrublands along a north-south gradient in Europe to seven years of experimental warming and drought: reductions in primary productivity in the heat and drought year of 2003, Global Change Biol., 13, 2563-2581, 2007.

Pfisterer, A. B., and Schmid, B.: Diversity-dependent production can decrease the stability of ecosystem functioning, Nature, 416 , 84-86, 2002.

Ruiz-Sánchez, M. C., Domingo, R., Torrecillas, A., and PérezPastor, A.: Water stress preconditioning to improve drought resistance in young apricot plants, Plant Sci., 156, 245-251, 2000.

Rustad, L. E., Campbell, J. L., Marion, G. M., Norby, R. J., Mitchell, M. J., Hartley, A. E., Cornelissen, J. H. C., and Gurevitch, J.: A meta-analysis of the response of soil respiration, net nitrogen mineralization, and aboveground plant growth to experimental ecosystem warming, Oecologia, 126, 543-562, 2001.

Scheffer, M., Carpenter, S., Foley, J. A., Folke, C., and Walker, B.: Catastrophic shifts in ecosystems, Nature, 413, 591-596, 2001.

Smith, M. D.: An ecological perspective on extreme climatic events: a synthetic definition and framework to guide future research, J. Ecol., 99, 656-663, 2011.

Van Peer, L., Nijs, I., Bogaert, J., Verelst, I., and Reheul, D.: Survival, gap formation, and recovery dynamics, in grassland ecosystems exposed to heat extremes: the role of species richness, Ecosystems, 4, 797-806, 2001.

Van Peer, L., Nijs, I., Reheul, D., and De Cauwer, B.: Species richness and susceptibility to heat and drought extremes in synthesized grassland ecosystems: compositional vs physiological effects, Funct. Ecol., 18, 769-778, 2004. 
van Ruijven, J., and Berendse, F.: Diversity enhances community recovery, but not resistance, after drought, J. Ecol., 98, 81-86, 2010.

Vilagrosa, A., Cortina, J., Gil-Pelegrin, E., and Bellot, J.: Suitability of drought-preconditioning techniques in Mediterranean climate, Restor. Ecol., 11, 208-216, 2003.

Villar-Salvador, P., Planelles, R., Oliet, J., Peñuelas-Rubira, J. L., Jacobs, D. F., and Gonzalez, M.: Drought tolerance and transplanting performance of holm oak (Quercus ilex) seedlings after drought hardening in the nursery, Tree Physiol., 24, 1147-1155, 2004.

Wahid, A., Gelani, S., Ashraf, M., and Foolad, M. R.: Heat tolerance in plants: an overview, Environ. Exp. Bot., 61, 199-223, 2007.

Walter, J., Nagy, L., Hein, R., Rascher, U., Beierkuhnlein, C., Willner, E., and Jentsch, A.: Do plants remember drought?, Hints towards a drought-memory in grasses, Environ. Exp. Bot., 71, 34-40, 2011.
Wang, Y. F., Yu, S. X., and Wang, J.: Biomass-dependent susceptibility to drought in experimental grassland communities, Ecol. Lett., 10, 401-410, 2007.

Xu, S., Li, J. L., Zhang, X. Q., Wei, H., and Cui, L. J.: Effects of heat acclimation pretreatment on changes of membrane lipid peroxidation, antioxidant metabolites, and ultrastructure of chloroplasts in two cool-season turfgrass species under heat stress, Environ. Exp. Bot., 56, 274-285, 2006.

Zavalloni, C., Gielen, B., Lemmens, C., De Boeck, H. J., Blasi, S. Van den Bergh, S., Nijs, I., and Ceulemans, R.: Does a warmer climate with frequent mild water shortages protect grassland communities against a prolonged drought?, Plant Soil, 308, 119130, 2008. 